\title{
Sodium deoxycholate-decorated zein nanoparticles for a stable colloidal drug delivery system
}

This article was published in the following Dove Press journal:

International Journal of Nanomedicine

\section{Agnese Gagliardi' \\ Donatella Paolino' \\ Michelangelo lannone ${ }^{2}$ \\ Ernesto Palma ${ }^{3}$ \\ Massimo Fresta ${ }^{3}$ \\ Donato $\mathrm{Cosco}^{3}$}

'Department of Experimental and Clinical Medicine, University "Magna Græcia" of Catanzaro, Catanzaro, Italy; ${ }^{2} \mathrm{CNR}$, Section of Pharmacology, Institute of Neurological Sciences, Borgia, Italy; ${ }^{3}$ Department of Health Sciences, University "Magna Græcia” of Catanzaro, Catanzaro, Italy
Correspondence: Massimo Fresta;

Donato Cosco

Department of Health Sciences, University "Magna Græcia” of Catanzaro, Campus Universitario "S. Venuta", Viale S. Venuta, I-88I00 Catanzaro, Italy

$\mathrm{Tel}+3909613694118$;

$+3909613694119$

Fax+3909613694237

Email fresta@unicz.it; donatocosco@unicz.it
Background: The use of biopolymers is increasing in drug delivery, thanks to the peculiar properties of these compounds such as their biodegradability, availability, and the possibility of modulating their physico-chemical characteristics. In particular, protein-based systems such as albumin are able to interact with many active compounds, modulating their biopharmaceutical properties. Zein is a protein of $20-40 \mathrm{kDa}$ made up of many hydrophobic amino acids, generally regarded as safe (GRAS) and used as a coating material.

Methods: In this investigation, zein was combined with various surfactants in order to obtain stable nanosystems by means of the nanoprecipitation technique. Specific parameters, eg, temperature, $\mathrm{pH}$ value, Turbiscan Stability Index, serum stability, in vitro cytotoxicity and entrapment efficiency of various model compounds were investigated, in order to identify the nanoformulation most useful for a systemic drug delivery application.

Results: The use of non-ionic and ionic surfactants such as Tween 80 , poloxamer 188 , and sodium deoxycholate allowed us to obtain nanoparticles characterized by a mean diameter of 100-200 nm when a protein concentration of $2 \mathrm{mg} / \mathrm{mL}$ was used. The surface charge was modulated by means of the protein concentration and the nature of the stabilizer. The most suitable nanoparticle formulation to be proposed as a colloidal drug delivery system was obtained using sodium deoxycholate $(1.25 \% \mathrm{w} / \mathrm{v})$ because it was characterized by a narrow size distribution, a good storage stability after freeze-drying and significant feature of retaining lipophilic and hydrophilic compounds.

Conclusion: The sodium deoxycholate-coated zein nanoparticles are stable biocompatible colloidal carriers to be used as useful drug delivery systems.

Keywords: nanoparticles, sodium deoxycholate, stabilizers, zein

\section{Introduction}

Both natural and synthetic polymers have been used for medical and pharmaceutical applications, and several are recognized as materials suitable for developing innovative formulations. ${ }^{1}$ Recently, proteins derived from plants have been receiving a certain degree of interest for potential application in the field of controlled drug delivery, ${ }^{2}$ thanks to their features of ample availability, great bio- and cyto-compatibility, poor immunogenicity in comparison with synthetic or semisynthetic polymers, and the possibility of modulating the physicochemical parameters of nanosystems. ${ }^{3}$ Considering the numerous advantages resulting from the use of plant proteins, various approaches were investigated in order to develop hydrogels, films, fibers, and nano- and microparticles for food-, biomedical, and drug delivery applications. ${ }^{4}$

In this investigation, we used zein, a natural hydrophobic protein belonging to alcohol-soluble prolamine-rich compounds abundantly contained in corn, for the preparation of polymer-based nanoparticles to be proposed as colloidal drug delivery devices. ${ }^{5}$ 
In 1985, zein received "GRAS" (generally regarded as safe) status by the US Food and Drug Administration (FDA) as a suitable material to be used for the film coating of oral pharmaceuticals. ${ }^{6}$ Based on solubility and sequence homology, zein has four classifications: $\alpha$-zein (characterized by a mean molecular weight of between 19 and $22 \mathrm{kDa}$ ), $\beta$-zein $(14 \mathrm{kDa})$, $\gamma$-zein (between 16 and $27 \mathrm{kDa}$ ), and $\delta$-zein $(10 \mathrm{kDa}) .{ }^{7}$ Over $50 \%$ of the amino acid residues of zein are non-polar, eg, leucine, proline, alanine, and phenylalanine, and this feature makes it one of the few natural proteins that can be solubilized in aqueous/ethanol solutions. ${ }^{8,9}$ Zein is also characterized by a high glutamine content which confers a certain polarity to the structure. ${ }^{6}$ Due to this amphiphilic character, the hydrophobic regions of zein can aggregate into colloidal particles which are able to retain lipophilic drugs, while the polar regions can interact with water-soluble compounds. ${ }^{10,11}$ This is why zein has been used to entrap drugs and nutraceuticals, eg, curcumin, ${ }^{12}$ 5-fluorouracil, ${ }^{13} \alpha$-tocopherol, ${ }^{14}$ lutein, ${ }^{15}$ glibenclamide, ${ }^{16}$ and essential oils. ${ }^{17}$ However, due to their low net charge close to the isoelectric point ( $\mathrm{pI} \approx 6.2$ ), the poor physical stability and dispersibility of freeze-dried zein nanoparticles at a neutral $\mathrm{pH}$ are detrimental to an efficacious application of this material in the alimentary and pharmaceutical fields. ${ }^{18}$ In this attempt, sodium caseinate, ${ }^{19}$ lecithin, Pluronic F68 ${ }^{\circledR},{ }^{20}$ and Tween $20^{\circledR}$ were used as stabilizers to prevent the colloidal aggregation of zein-based nanosystems by decreasing their hydrophobic attraction and increasing steric repulsion. ${ }^{20-23}$

The aim of this investigation was to evaluate the influence of several factors on the preparation of stable zein nanoparticles made up of yellow derivative, in order to develop a colloidal formulation useful for drug delivery. In particular, experimentation was focused on the physicochemical characterization of zein nanoparticles prepared in the presence of various surfactants, their stability in serum as a function of temperature and different $\mathrm{pH}$ values, as well as freeze-drying experiments using various cryoprotectants. The toxicity of the zein-based colloidal formulations was also investigated on the different cell lines used. Moreover, the entrapment efficiency (EE\%) of various hydrophobic and hydrophilic drugs was evaluated.

\section{Materials and methods Materials}

Yellow zein, sodium deoxycholate monohydrate (SD), alltrans-retinoic acid (ATRA), red oil, rhodamine B, 3-[4,5dimethylthiazol-2-yl]-3,5-diphenyltetrazolium bromide salt (used for MTT-tests), phosphate buffered saline (PBS) tablets, dimethyl sulfoxide, and amphothericin B solution $(250 \mu \mathrm{g}$ / $\mathrm{mL}$ ), were purchased from Sigma-Aldrich Co. (St Louis, MO, USA). Tween 80 (T80) was provided by Acef S.p.a.
(Piacenza, Italy). Poloxamer 188 (PLX188) was purchased from BASF (Ludwigshafen, Germany). Ethanol was obtained from Carlo Erba SpA (Rodano [MI], Italy), while cellulose membrane Spectra/Por MWCO 50 kDA was obtained from Spectrum Laboratories Inc. (Eindhoven, the Netherlands).

For the in vitro studies, Dulbecco's Modified Eagle's Medium (DMEM) and Roswell Park Memorial Institute1640 enriched with Glutamax I, tripsin/EDTA, penicillin/streptomycin solution and fetal bovine serum (FBS) were obtained from Gibco (Thermo Fisher Scientific, Waltham, MA, USA). A549 and K562 cells were purchased from the IRCCS Azienda Ospedaliera Universitaria San Martino - IST Istituto Nazionale per la Ricerca sul Cancro.

\section{Preparation of zein nanoparticles}

Zein nanoparticles were obtained using the nanoprecipitation method of the preformed polymer in an aqueous solution. ${ }^{24}$ Briefly, various amounts of zein were dissolved in $3 \mathrm{~mL}$ of an ethanol/water solution $(2: 1 \mathrm{v} / \mathrm{v})$ at room temperature and added to $5 \mathrm{~mL}$ of aqueous phase made up of MilliQ water containing different amounts of surfactants (Table 1), homogenized using an Ultraturrax ${ }^{\circledR}$ (model T25; IKA ${ }^{\circledR}$ Werke GmbH and Co, Staufen, Germany) at 24,000 rpm for $1 \mathrm{~min}$ and then mechanically stirred at $600 \mathrm{rpm}$ for $12 \mathrm{~h}$ on a magnetic plate to favor the evaporation of the organic solvent. The nanoparticles were suitably purified by means of a dialysis technique (cut-off $50 \mathrm{kDa}$ ), which removed the unreacted compounds.

\section{Physicochemical and stability evaluation}

Mean size, size distribution, and the Z-potential of the nanoparticles were evaluated with a Zetasizer Nano ZS (a dynamic light scattering spectrophotometer made by Malvern Instruments Ltd., Malvern, UK), using the thirdorder cumulant fitting as the correlation function. ${ }^{25}$ The results were expressed as the mean of three different experiments \pm standard deviation. Transmission electron microscopy (TEM) was performed according to a procedure described elsewhere. ${ }^{26}$

The nanoparticle formulations were also submitted to Turbiscan $\mathrm{Lab}^{\circledR}$ Expert (Formulaction, Toulouse, France) analysis in order to evaluate their stability profiles as a function of temperature and storage time. ${ }^{27}$ The instrument was equipped with a Turby Soft 2.0 for data processing, and the results were reported as kinetic stability profile vs time.

The influence of the $\mathrm{pH}$ on the modulation of the physicochemical properties of the various zein-based formulations was investigated by dispersing the samples in deionized water at different $\mathrm{pH}$ values $(4.0,6.0,8.0,10.0)$, using $1 \mathrm{~mol} / \mathrm{L} \mathrm{NaOH}$ or $\mathrm{HCl}$. 
Table I Composition and physico-chemical properties of zein nanoformulations

\begin{tabular}{|c|c|c|c|c|c|c|c|}
\hline Sample & $\begin{array}{l}\text { Zein } \\
\text { (mg) }\end{array}$ & $\begin{array}{l}\text { T80 } \\
(\% \mathrm{w} / \mathrm{v})\end{array}$ & $\begin{array}{l}\text { PLXI88 } \\
\text { (\% w/v) }\end{array}$ & $\begin{array}{l}\text { SD } \\
(\% \text { w/v) }\end{array}$ & $\begin{array}{l}\text { Mean sizes } \\
(\mathrm{nm})\end{array}$ & $\begin{array}{l}\text { Polydispersity } \\
\text { index }\end{array}$ & $\begin{array}{l}\text { Zeta potential } \\
(\mathrm{mV})\end{array}$ \\
\hline A & 1 & - & - & - & $401 \pm 16$ & $0.28 \pm 0.14$ & $-14 \pm 1.2$ \\
\hline B & 2 & - & - & - & $312 \pm 9$ & $0.25 \pm 0.01$ & $-2.8 \pm 0.5$ \\
\hline C & 3 & - & - & - & $|40 \pm|$ & $0.23 \pm 0.01$ & $5.8 \pm 1.4$ \\
\hline D & 4 & - & - & - & $|3| \pm \mid$ & $0.21 \pm 0.01$ & $7.0 \pm 0.6$ \\
\hline$E$ & 5 & - & - & - & $|20 \pm|$ & $0.22 \pm 0.01$ & $12 \pm 1.3$ \\
\hline$F$ & 10 & - & - & - & $106 \pm 1$ & $0.20 \pm 0.0 \mathrm{I}$ & $20 \pm 0.2$ \\
\hline G & 12 & - & - & - & $115 \pm 1$ & $0.42 \pm 0.01$ & $30 \pm 0.6$ \\
\hline $\mathrm{H}$ & 15 & - & - & - & $|4| \pm 3$ & $0.53 \pm 0.02$ & $30 \pm 1.3$ \\
\hline I & 10 & 1.25 & - & - & $274 \pm 19$ & $0.5 I \pm 0.09$ & $9.3 \pm 0.6$ \\
\hline $\mathrm{L}$ & 10 & 2.5 & - & - & $|27 \pm|$ & $0.17 \pm 0.01$ & $12 \pm 0.6$ \\
\hline$M$ & 10 & 5 & - & - & $|37 \pm|$ & $0.23 \pm 0.01$ & $10 \pm 1.6$ \\
\hline $\mathrm{N}$ & 10 & - & 1.25 & - & $106 \pm 1$ & $0.21 \pm 0.03$ & $20 \pm 0.6$ \\
\hline O & 10 & - & 2.5 & - & $103 \pm 1$ & $0.18 \pm 0.01$ & $33 \pm 4.8$ \\
\hline$P$ & 10 & - & 5 & - & $93.57 \pm 1$ & $0.12 \pm 0.01$ & $2 \mathrm{I} \pm 2.4$ \\
\hline $\mathrm{Q}$ & 10 & - & - & 1.25 & $110 \pm 1$ & $0.1 I \pm 0.01$ & $-34 \pm 2.9$ \\
\hline$R$ & 10 & - & - & 2.5 & $306 \pm 153$ & $0.45 \pm 0.06$ & $-42 \pm I . I$ \\
\hline S & 10 & - & - & 5 & $>1,000$ & $0.72 \pm 0.15$ & $-37 \pm 4.7$ \\
\hline
\end{tabular}

Note: Data are presented as mean \pm standard deviation.

Abbreviations: T80, Tween $80^{\circledR}$; PLXI88, Poloxamer I88 ${ }^{\circledR}$; SD, sodium deoxycholate monohydrate.

\section{Nanoparticle stability in serum}

The influence of serum protein on the stability of the various zein nanoparticle formulations was investigated following their incubation in $70 \%$ FBS. ${ }^{26}$ Briefly, the various nanoparticle suspensions $(200 \mu \mathrm{L})$ were added to $1 \mathrm{~mL}$ of FBS solution and incubated at $37^{\circ} \mathrm{C}$ for $48 \mathrm{~h}$, stirring at $600 \mathrm{rpm}$. The samples were analyzed at different incubation times, and their average size was measured as reported above.

\section{Freeze drying of nanoparticles}

The zein nanoparticles were lyophilized using a freezedrying system (VirTis SP scientific sentry 2.0; SP Industries, Warminster, PA, USA) equipped with a vacuum pump (B14 model; Carpanelli S.p.a., Bologna, Italy). Various samples $(0.5 \mathrm{~mL})$ were enriched with different cryoprotectants (glucose, trehalose, sucrose, mannose, mannitol) at various concentrations ( 5 and $10 \% \mathrm{w} / \mathrm{v}$ ), transferred into pyrex glass vials, and frozen in liquid nitrogen for $2 \mathrm{~min}$. The samples were then placed in the freeze-drying chamber and subjected to cryo-drying for $24 \mathrm{~h}$. The resulting powder was stored at room temperature for 1 week, and then it was rehydrated with the same volume of sublimated water by manual shaking and then submitted to physicochemical analysis (size and surface charge evaluation).

\section{Cell cultures and in vitro cytotoxicity}

A549 (human lung cancer cells) and K562 (human chronic myelogenous leukemia cells) were incubated in plastic culture dishes $(100 \times 20 \mathrm{~mm})$ in a Water-Jacketed $\mathrm{CO}_{2}$ incubator at $37^{\circ} \mathrm{C}\left(5 \% \mathrm{CO}_{2}\right)$ using a DMEM with glutamine and Roswell Park Memorial Institute 1640, respectively, supplemented with penicillin $(100 \mathrm{UI} / \mathrm{mL})$, streptomycin $(100 \mu \mathrm{g} /$ $\mathrm{mL})$, amphotericin B $(250 \mu \mathrm{g} / \mathrm{mL})$, and FBS $(10 \%, \mathrm{v} / \mathrm{v})$, as previously described. ${ }^{28,29}$

To investigate the cytotoxicity of zein nanoparticles with and without surfactants, MTT-testing was carried out. ${ }^{25,29}$ Briefly, cells were plated in 96-well culture dishes $\left(5 \times 10^{3}\right.$ cells $/ 0.2 \mathrm{~mL}$ for $\mathrm{A} 549$ cells and $10 \times 10^{3}$ cells/ $0.2 \mathrm{~mL}$ for K562) and treated with different amounts of nanoparticles $(1,10,50$, and $100 \mu \mathrm{g} / \mathrm{mL}$ of protein) at various incubation times $(24,48$, and $72 \mathrm{~h})$. Untreated cells were used as control. After each incubation period, $20 \mu \mathrm{L}$ of tetrazolium salt solubilized in PBS $(5 \mathrm{mg} / \mathrm{mL})$ was added to each well, and the plates were incubated again for $3 \mathrm{~h}$. The plates containing the K562 cells were centrifuged at 1,500 rpm for $5 \mathrm{~min}$ (ALC PK130 Centrifuge; Thermo Fisher Scientific), in order to obtain the deposition of salts on the bottom of the wells.

Successively, the medium was removed, and the formazan salts precipitated on the well bottoms were dissolved with $200 \mu \mathrm{L}$ of a mixture of dimethyl sulfoxide/ethanol $(1: 1 \mathrm{v} / \mathrm{v})$ by shaking the plates for $20 \mathrm{~min}$ at $230 \mathrm{rpm}\left(\mathrm{IKA}^{\circledR} \mathrm{KS}\right.$ 130 Control, IKA ${ }^{\circledR}$; Werke $\mathrm{GmbH}$ and Co.). The solubilized formazan was analyzed with a microplate spectrophotometer (xMARK ${ }^{\mathrm{TM}}$; Bio-Rad Laboratories Inc., Hercules, CA, USA) at a wavelength of $540 \mathrm{~nm}$, with reference at $690 \mathrm{~nm}$. Cell viability, expressed as a percentage, was reported as the mean 
of five different experiments \pm standard deviation, and was obtained through the following equation, in which $\mathrm{Abs}_{\mathrm{T}}$ is the absorbance of treated cells and $\mathrm{Abs}_{\mathrm{C}}$ is the absorbance of control (untreated) cells:

$$
\text { Cell viability }(\%)=\frac{\mathrm{Abs}_{\mathrm{T}}}{\mathrm{Abs}_{\mathrm{C}}} \times 100
$$

\section{EE\% of model drugs}

The EE\% of hydrophilic (Rhodamine B) and hydrophobic compounds (Red Oil and ATRA) in zein nanoparticles was evaluated by means of suitable spectrophotometric analyses.

The colloidal formulations prepared with various amounts of drugs (20-200 $\mu \mathrm{g} / \mathrm{mL})$ were centrifuged at $90 \mathrm{k} \mathrm{rpm}$ for 1 h using a Beckman Optima ${ }^{\mathrm{TM}}$ Ultracentrifuge (Fullerton, Canada). The pellets were disaggregated by a sonicator (UW70; Bandelin Electronic GmbH \& Co. KG, Berlin, Germany) and incubated in water or ethanol as a function of the entrapped compound. The amount of $\operatorname{drug}(\mathrm{s})$ contained in the solutions was spectrophotometrically determined (Lambda 35; Perkin Elmer, Waltham, MA, USA) at $\lambda_{\max }$ $553 \mathrm{~nm}, 544 \mathrm{~nm}$, and $350 \mathrm{~nm}$ for Red Oil, Rhodamine B, and ATRA, respectively. No interference deriving from the empty zein formulations was observed. The amount of drug entrapped in the nanoparticles was determined as the difference between the amount added during the nanoparticle preparation and the unentrapped amount. The EE\% was expressed as the percentage of the total amount of drug that became entrapped, according to the following equation:

$$
\mathrm{EE} \%=\frac{\mathrm{De}}{\mathrm{Da}} \times 100
$$

where De is the amount of entrapped drug and Da is the drug amount added during preparation of the nanoparticles.

\section{Statistical analysis}

Statistical analysis of the various experiments was performed by ANOVA, and the results were confirmed by a Bonferroni $t$-test, with a $P$-value of $<0.05$ considered statistically significant.

\section{Results and discussion \\ Physico-chemical characterization}

Various amounts of zein were nanoprecipitated in order to evaluate the average size, polydispersity index, and surface charges of nanoparticles (Table 1); these parameters are of great importance for a carrier to be proposed for systemic administration. In fact, the possibility of modifying these parameters is fundamental to achieve smart nanodevices, the physicochemical features of which have to be modulated as a function of therapeutic requirements. ${ }^{30}$

As reported in Table 1, the samples showed a mean diameter of $\sim 100-150 \mathrm{~nm}$ and a smooth morphology when the amount of zein was $\geq 3 \mathrm{mg}$, thus evidencing a correlation between the protein concentration and the formation of well-defined colloidal structures (Figure S1). On the other hand, aggregates were obtained when more than $10 \mathrm{mg}$ of zein $(2 \mathrm{mg} / \mathrm{mL})$ were initially used, as demonstrated by the high values resulting on the polydispersity index (Table 1), which is in agreement with data previously reported. ${ }^{15}$

Interestingly, the surface charges were negative when 1 or $2 \mathrm{mg}$ of zein were used, while the zeta-potential shifted towards positive values when the polymer concentration was increased (Table 1). A possible explanation of this finding could be due to the modulation of the protein conformation, or to non-covalent binding between the various molecules of the compound.

The nanoparticles obtained using $10 \mathrm{mg}$ of zein $(2 \mathrm{mg} / \mathrm{mL}$, sample F) were chosen for further investigation, because no aggregates were observed during their preparation, and they were able to retain a suitable amount of $\operatorname{drug}(\mathrm{s})$.

The addition of various surfactants during the preparation of the zein nanoparticles allowed the formation of stable complexes by reducing the hydrophobic attraction of the lipophilic residues and increasing colloidal repulsion; ${ }^{20}$ in particular, the influence of these surfactants (T80, PLX188, and SD) on the physicochemical characteristics of the zein nanoparticles was evaluated (Table 1). Namely, the addition of non-ionic surfactants to the water phase produced homogeneous, monodispersed zein nanoparticles. The amounts of $2.5 \%$ and $5 \% \mathrm{w} / \mathrm{v}$ of T80 and PLX188, respectively, produced nanoparticles with a mean size of $\sim 100 \mathrm{~nm}$ and a narrow size distribution (Table 1). No significant influence on the surface charges of the zein nanoparticles was elicited by PLX188, while the addition of T80 elicited a significant decrease in this parameter. In fact, the $\sim 20 \mathrm{mV}$ zeta-potential of surfactantfree zein nanoparticles decreased to $\sim 10 \mathrm{mV}$ when T80 was used (Table 1). This finding may be due to the adsorption of the surfactant onto the particle surface, leading to a modulation of the shearing plane as a consequence of the interaction between the polysorbate-residues and the protein. ${ }^{15}$

The addition of moderate amounts of SD $(1.25 \% \mathrm{w} / \mathrm{v})$, an anionic surfactant, did not influence the mean nanoparticle size, but greater concentrations of surfactant induced a significant increase in the particle size, as well as the formation 
of macroaggregates (Table 1). The addition of SD also influenced the surface charge of the nanoparticles, shifting the zeta-potential from positive to negative values. This is probably a result of the binding between the negativelycharged headgroups of SD with the positively charged amino acid moieties of zein, which would lead to significant exposure of the negatively-charged residues. ${ }^{31}$

The morphological analysis carried out by TEM evidenced a spherical shape of the various zein nanoformulations, and confirmed the data obtained by dynamic light scattering (DLS) (Figure 1).

Turbiscan Lab analyses were carried out to evaluate the stability profile of the various nanoparticle formulations as a function of incubation time and temperature, and the obtained data were expressed as Turbiscan Stability Index (TSI). ${ }^{32}$ As shown in Figure 1, the TSI results for the various surfactant-free zein nanoparticles at $20^{\circ} \mathrm{C}$ are very similar, thus evidencing the absence of destabilizing phenomena, eg, sedimentation, migration, and/or flocculation. ${ }^{27}$ When the temperature was increased to $37^{\circ} \mathrm{C}$, a significant variation in the TSI showed on the sample prepared with $5 \mathrm{mg}$ of zein, probably as a consequence of the specific rearrangement of the protein; on the contrary, the formulation prepared with $10 \mathrm{mg}$ of protein showed suitable stability. The TSI profiles of the samples prepared with 12 and $15 \mathrm{mg}$ of zein confirmed the DLS data by evidencing the sedimentation of the macroaggregates (data not shown).

The TSI profiles of the zein nanoparticles prepared with surfactants further confirmed the stabilizing effect of the surfactant on the colloidal structure (Figure 2). In fact, the TSI profiles of the nanoparticles containing $2 \mathrm{mg} / \mathrm{mL}$ of protein (Sample F) and prepared with the surfactants PLX188 $5 \%$, T80 2.5\% w/v, and SD 1.25\% showed no significant modification either at $20^{\circ} \mathrm{C}$ or $37^{\circ} \mathrm{C}$ (Figure 2). Other concentrations of stabilizers provided no improvement in the TSI profiles, confirming the DLS results (Figure S2).

\section{Effect of $\mathrm{pH}$}

Many pharmaceutical formulations are administered at various $\mathrm{pHs}$ as a function of the body compartment to be reached and the pharmacological effect to be exerted by the entrapped compound. ${ }^{33}$ Therefore, it is important to investigate the
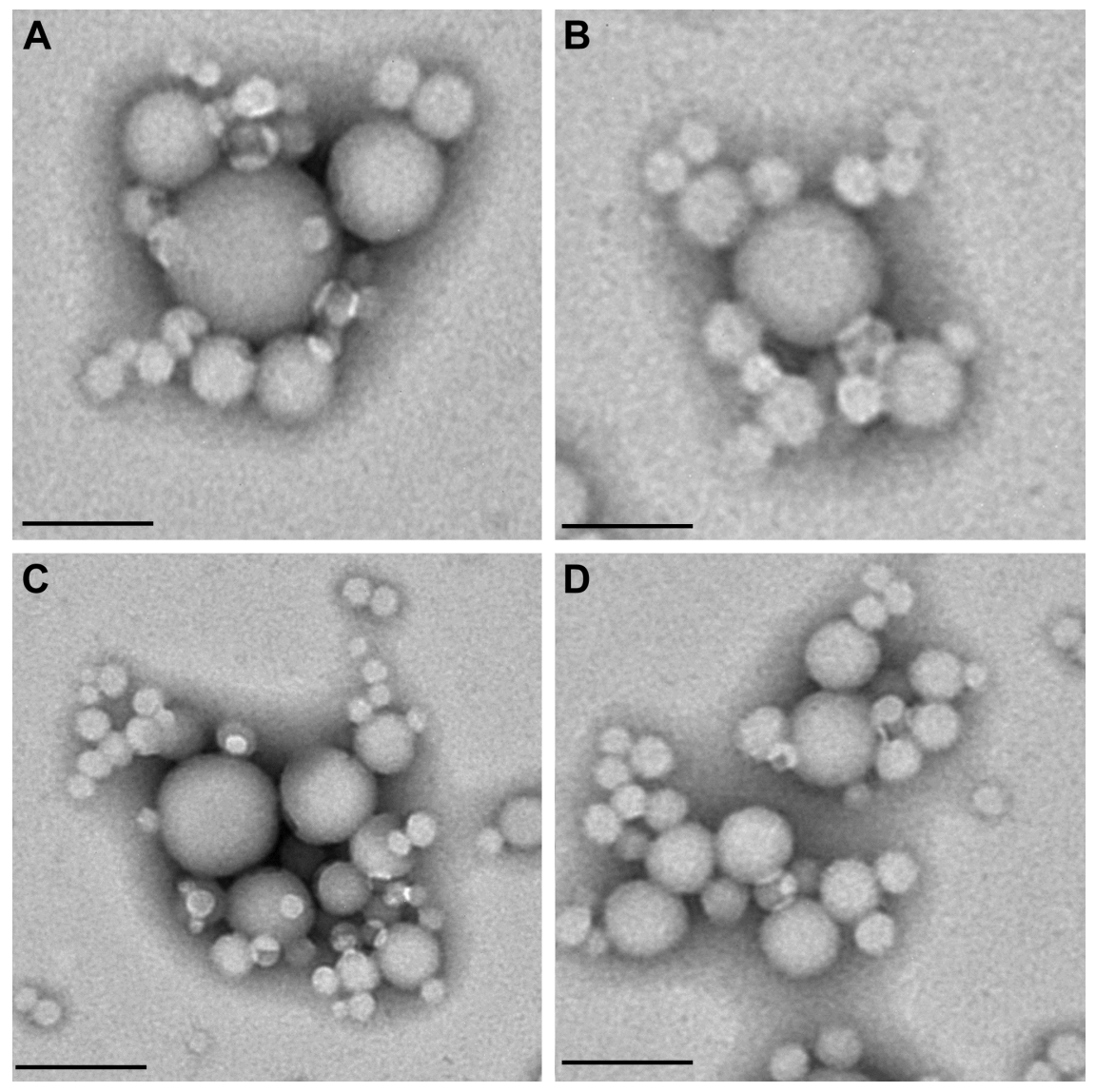

Figure I TEM analysis of $(\mathbf{A})$ surfactant-free zein nanoparticles $(2 \mathrm{mg} / \mathrm{mL}$ of protein), and of zein nanosystems prepared with (B) PLXI88 (5\% w/v), (C) T80 (2.5\% w/v), or (D) SD (1.25\% w/v). Scale bar $=200 \mathrm{~nm}$.

Abbreviations: TEM, transmission electron microscopy; T80, Tween $80^{\circledR}$; PLXI88, Poloxamer $188^{\circledR}$; SD, sodium deoxycholate monohydrate. 

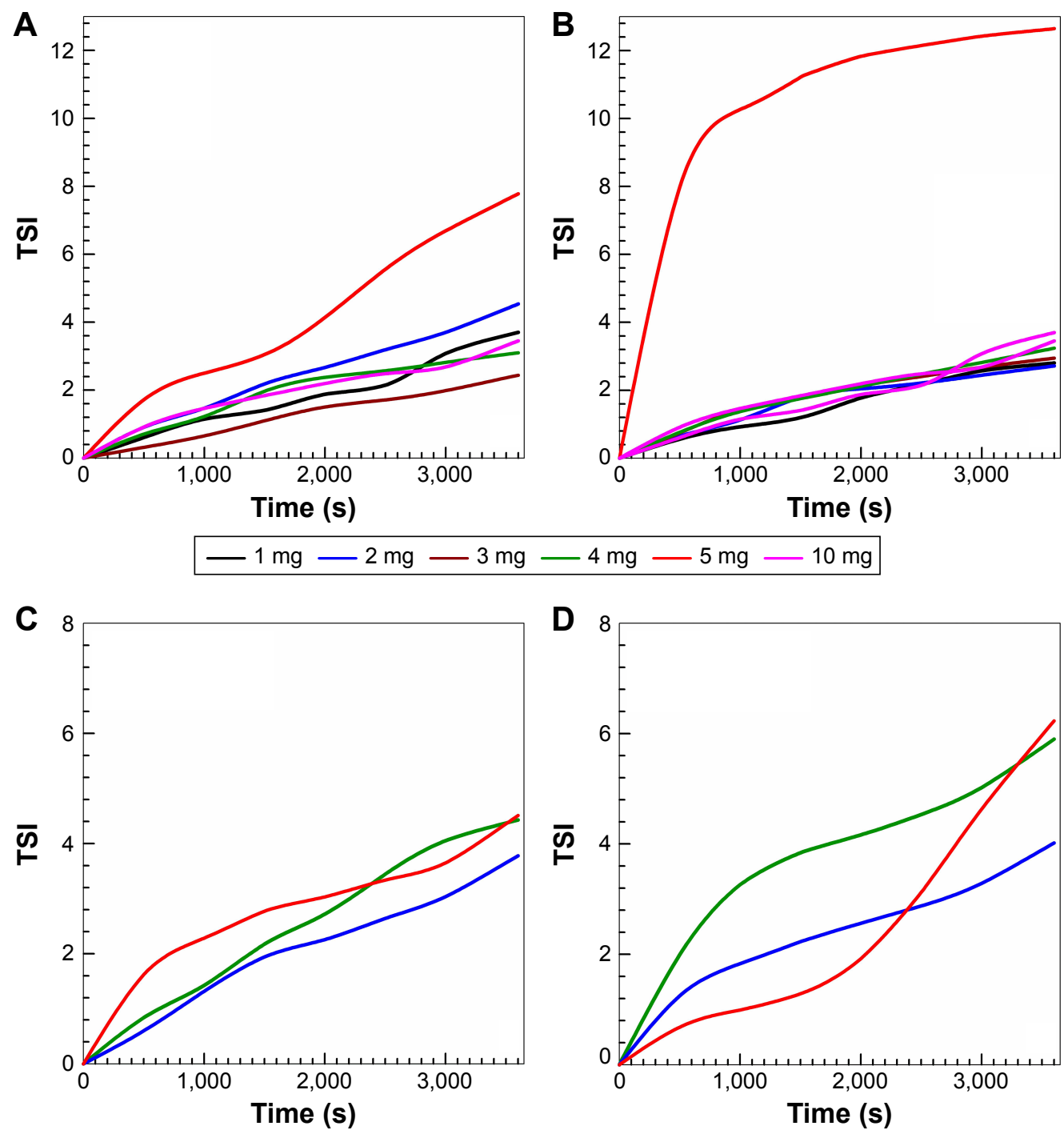

- T80 2.5\% w/v - PLX188 5\% w/v - SD 1.25\% w/v

Figure 2 TSI of surfactant-free zein nanoparticles as a function of zein concentration $(\mathbf{A}$ and $\mathbf{B})$. TSI of zein nanoparticles $(2 \mathrm{mg} / \mathrm{mL}$ of protein) prepared with various surfactants (PLXI88 5\% w/v, T80 2.5\% w/v, and SD I.25\% w/v) (C and D). $\mathbf{T}=20^{\circ} \mathrm{C}(\mathbf{A}$ and $\mathbf{C}) ; \mathrm{T}=37^{\circ} \mathrm{C}$ (B and D).

Abbreviations: TSI, Turbiscan Stability Index; T80, Tween 80 ${ }^{\circledast}$; PLXI88, Poloxamer 188${ }^{\circledast}$; SD, sodium deoxycholate monohydrate; T, temperature.

influence of the $\mathrm{pH}$ on the physicochemical parameters of zein nanoparticles.

As shown in Figure 3, the sizes of the various nanoparticles were evaluated as a function of different $\mathrm{pHs}$. Surfactant-free zein nanoparticles preserved their mean diameter $(<300 \mathrm{~nm})$ only at $\mathrm{pH} 4.0$, while a significant increase $(>1,000 \mathrm{~nm})$ was observed at $\mathrm{pH}$ values greater than 6.0 , probably as a consequence of destabilizing phenomena related to the isoelectric point of protein (pI 6.2). The zeta potential of the zein nanoparticles showed a gradual decrease when the incubation medium moved from acidic to alkaline conditions, probably as a consequence of the modulation of the shearing plane characteristics (Table 2).
The presence of non-ionic surfactants during preparation prevented the formation of zein macroaggregates and, hence, the sedimentation and the surface charges of the nanoparticles showed a zeta potential $( \pm 10 \mathrm{mV})$ close to neutrality (Table 2) only at pHs 4.0 and 8.0. Also in this case, the $\mathrm{pH}$ close to the $\mathrm{pI}$ of protein caused a lack of stability, thus confirming the previous data. ${ }^{15}$

The use of SD provided the most suitable results in terms of zein nanoparticle stability by showing no significant variation in the mean size and only a slight decrease in zeta potential at basic $\mathrm{pH}$, further confirming the strong contribution of this surfactant to the colloidal stability of zein nanoparticles (Figure 3 and Table 2). Sodium cholate 


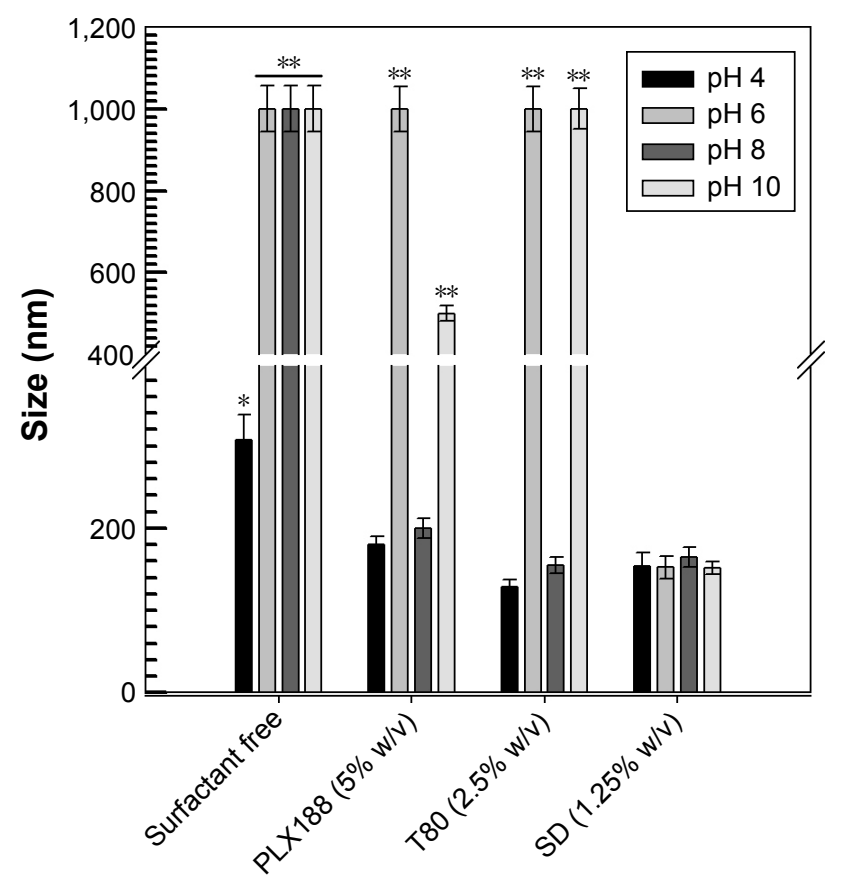

Figure 3 Influence of $\mathrm{pH}$ on the mean diameter of zein nanoparticles prepared using a protein concentration of $2 \mathrm{mg} / \mathrm{mL}$. Statistical analysis by one-way ANOVA and a posteriori Bonferroni $t$-test: $* P<0.05$; $* * P<0.001$.

Abbreviations: T80, Tween $80^{\circledR}$; PLXI88, Poloxamer 188 ${ }^{\circledR}$; SD, sodium deoxycholate monohydrate; $\mathrm{T}$, temperature.

derivatives merely demonstrated their ability to stabilize various colloidal polymeric structures, as was true in the case of polyesters with respect to other surfactants such as PVA and polysorbates. ${ }^{34}$

\section{Effect of heating}

Heating is an important parameter to be investigated in order to establish the thermal stability of a colloidal system, which is evaluated during the preformulation phases of a pharmaceutical. ${ }^{35}$ For this reason, the influence of the temperature on the various zein nanoparticles was investigated. The surfactant-free formulation showed a considerable

Table 2 Effects of $\mathrm{pH}$ on the zeta potential of zein nanosystems prepared using a protein concentration of $2 \mathrm{mg} / \mathrm{mL}$

\begin{tabular}{lllll}
\hline Sample & $\mathbf{p H}$ & & \\
\cline { 2 - 5 } & $\mathbf{4}$ & $\mathbf{6}$ & $\mathbf{8}$ & $\mathbf{1 0}$ \\
\hline Zeta potential $(\mathbf{m V})$ & & & \\
Surfactant free & $41.2 \pm 0.7$ & $-9.64 \pm 4.4$ & $-12.7 \pm 2.2$ & $-22.7 \pm 3.9$ \\
T80 & $29.3 \pm 2.6$ & $-7.85 \pm 4.3$ & $17.1 \pm 0.8$ & $-3 \pm 2.3$ \\
$\mathrm{PLX188^{ \textrm {b } }}$ & $35.8 \pm 2.1$ & $-7.7 \pm 1.2$ & $9.14 \pm 0.3$ & $-1 \pm 6.4$ \\
$\mathrm{SD}^{\mathrm{c}}$ & $-25.6 \pm 0.9$ & $-28.5 \pm 2.2$ & $-38.1 \pm 0.9$ & $-39.1 \pm 0.6$ \\
\hline
\end{tabular}

Notes: ${ }^{\mathrm{a}} 2.5 \%(\mathrm{w} / \mathrm{v}) .{ }^{\mathrm{b}} 5 \%(\mathrm{w} / \mathrm{v}) .{ }^{\mathrm{c}} \mathrm{l} .25 \%(\mathrm{w} / \mathrm{v})$. Data are presented as mean \pm standard deviation.

Abbreviations: T80, Tween $80^{\circledR}$; PLXI88, Poloxamer I88 ${ }^{\circledR}$; SD, sodium deoxycholate monohydrate.
Table 3 Effect of heating on the physico-chemical parameters of the various zein formulations prepared by a protein concentration of $2 \mathrm{mg} / \mathrm{mL}$

\begin{tabular}{lllll}
\hline Sample & $\begin{array}{l}\text { Temperature } \\
\left({ }^{\circ} \mathbf{C}\right)\end{array}$ & $\begin{array}{l}\text { Mean } \\
\text { size }(\mathbf{n m})\end{array}$ & $\begin{array}{l}\text { Polydispersity } \\
\text { index }\end{array}$ & $\begin{array}{l}\text { Zeta } \\
\text { potential } \\
(\mathbf{m V})\end{array}$ \\
\hline Surfactant & 30 & $144 \pm 9$ & $0.17 \pm 0.02$ & $5.7 \pm 0.2$ \\
free & 40 & $>1,000$ & $0.64 \pm 0.07$ & $-18.1 \pm 0.1$ \\
& 50 & $>1,000$ & $0.72 \pm 0.08$ & $-20.1 \pm 0.1$ \\
T80 & 30 & $127 \pm 2$ & $0.21 \pm 0.01$ & $9.3 \pm 1.1$ \\
$(2.5 \% \mathrm{w} / \mathrm{v})$ & 40 & $131 \pm 1$ & $0.24 \pm 0.01$ & $11.9 \pm 0.5$ \\
& 50 & $130 \pm 2$ & $0.20 \pm 0.01$ & $12.2 \pm 0.6$ \\
$\mathrm{PLXI} 88$ & 30 & $132 \pm 2$ & $0.18 \pm 0.03$ & $6.6 \pm 0.3$ \\
$(5 \% \mathrm{w} / \mathrm{v})$ & 40 & $140 \pm 1$ & $0.14 \pm 0.02$ & $5.7 \pm 0.2$ \\
& 50 & $147 \pm 1$ & $0.11 \pm 0.01$ & $9.51 \pm 0.3$ \\
$\mathrm{SD}$ & 30 & $126 \pm 1$ & $0.12 \pm 0.01$ & $-33.8 \pm 2.6$ \\
$(\mathrm{I} .25 \% \mathrm{w} / \mathrm{v})$ & 40 & $126 \pm 2$ & $0.13 \pm 0.02$ & $-34.7 \pm 2.2$ \\
& 50 & $128 \pm 1$ & $0.15 \pm 0.02$ & $-28.9 \pm 1.2$ \\
\hline
\end{tabular}

Note: Data are presented as mean \pm standard deviation.

Abbreviations: T80, Tween $80^{\circledR}$; PLXI88, Poloxamer I88 ${ }^{\circledR}$; SD, sodium deoxycholate monohydrate.

increase of size and polydispersity index when it was heated, while the zeta potential analysis provided negative values (Table 3). This finding suggested that the temperature increase probably caused a rearrangement of the protein and the collapse of the colloidal structure. ${ }^{14}$ The addition of ionic and non-ionic surfactants during preparation of the nanoparticles significantly improved the colloidal stability of the nanoparticles against the destabilizing phenomena promoted by the heating process; this trend further confirms their fundamental role in developing a suitable formulation for efficient drug delivery.

\section{Serum stability}

The behavior of zein nanoparticles in medium containing serum is another essential issue to be investigated before using these colloids in in vitro and in vivo experiments. In fact, serum proteins may interact with nanosystems inducing the formation of a corona, which is able to promote the binding of biomolecules to the surfaces of the nanoparticles as well as increase their hydrodynamic ray. ${ }^{26,36}$

Zein nanoparticles were incubated in $70 \% \mathrm{FBS}$ at $37^{\circ} \mathrm{C}$, and their size was monitored up to $48 \mathrm{~h}$. The surfactant-free nanoparticles showed an increase of the mean size in the first few hours and then remained unmodified up to $48 \mathrm{~h}$ (Figure 4). Interestingly, the use of T80 elicited an increase of the mean size of the nanoparticles similar to that observed for surfactant-free nanoparticles, even though this trend was emphasized as a function of the incubation times, ie, the longer the incubation the greater the size increase. The obtained 


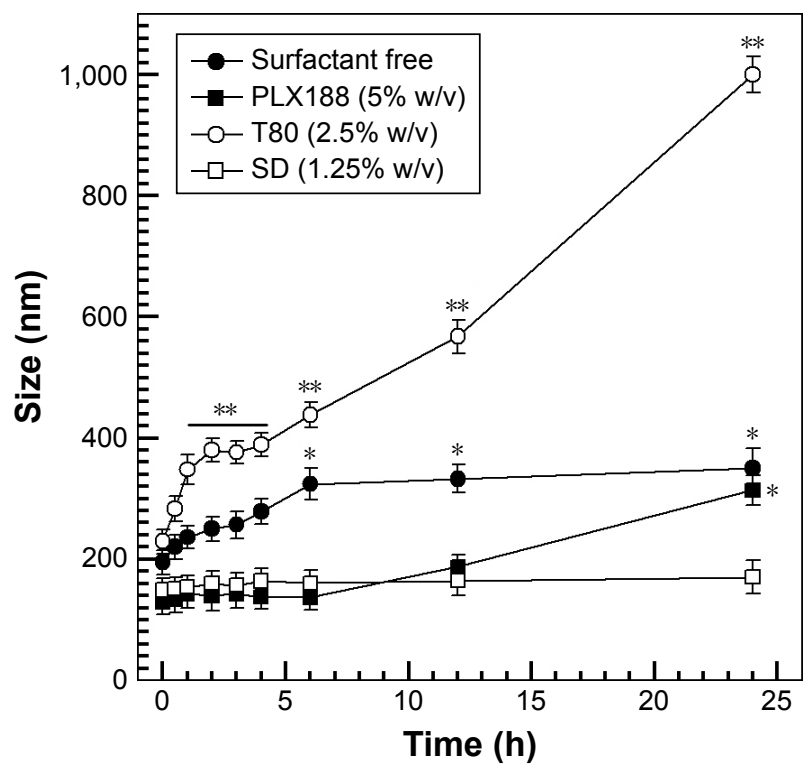

Figure 4 Serum stability of zein nanoparticles prepared using a protein concentration of $2 \mathrm{mg} / \mathrm{mL}$ in $70 \% \mathrm{FBS}$ as a function of time. Statistical analysis by one-way ANOVA and a posteriori Bonferroni $t$-test: $* P<0.05 ; * * P<0.001$.

Abbreviations: FBS, fetal bovine serum; T80, Tween $80^{\circledR}$; PLXI88, Poloxamer $188^{\circledR}$; SD, sodium deoxycholate monohydrate.

results confirm the ability of polysorbate derivatives to adsorb protein onto the surface of various colloids. ${ }^{37}$

Conversely, the zein nanoparticles prepared in the presence of PLX188- and SD-provided suitable serum stability by showing an average size $<200 \mathrm{~nm}$ for up to $24 \mathrm{~h}$. This feature is appealing for possible in vivo administration of zein nanoparticles, because the change in the physicochemical properties of the colloidal systems, caused by the adsorption of the serum protein, still remains an open issue to be investigated.

\section{Freeze-drying of zein nanoparticles}

The evaluation of the physicochemical features of a colloidal system following a freeze-drying process is required in order to forecast its long-term storage stability, so that a nanoparticle formulation with a long shelf-life can be designed, thus increasing the potentiality of its marketability. For this reason, lyophilization studies were carried out on the various zein nanoparticles as a function of different cryoprotectant agents.

As shown in Table 4, the formulation prepared with SD provided the best results in terms of ability to be resuspended after the freeze-drying procedure, except for mannose $10 \%$ and glucose $10 \%$, both of which evidenced a significant increase in the particle size and polydispersity. Moreover, the anionic surfactant-coated nanoparticles were
Table 4 Physico-chemical properties of zein nanoparticles prepared using a protein concentration of $2 \mathrm{mg} / \mathrm{mL}$ after the freezedrying process as a function of surfactant and cryoprotectant used

\begin{tabular}{|c|c|c|c|c|}
\hline Sample & $\begin{array}{l}\text { Cryoprotectant } \\
\text { (\% w/v) }\end{array}$ & $\begin{array}{l}\text { Mean } \\
\text { size } \\
(\mathrm{nm})\end{array}$ & $\begin{array}{l}\text { Polydispersity } \\
\text { index }\end{array}$ & $\begin{array}{l}\text { Zeta } \\
\text { potential } \\
(\mathrm{mV})\end{array}$ \\
\hline Surfactant & Glucose $5 \%$ & $836 \pm 41$ & $0.7 I \pm 0.03$ & $-4.4 \pm 0.1$ \\
\hline \multirow[t]{9}{*}{ free } & Glucose $10 \%$ & $435 \pm 20$ & $0.62 \pm 0.04$ & $-3.5 \pm 0.1$ \\
\hline & Trehalose $5 \%$ & $691 \pm 34$ & $0.63 \pm 0.03$ & $-5.4 \pm 0.1$ \\
\hline & Trehalose $10 \%$ & $695 \pm 34$ & $0.59 \pm 0.02$ & $1.2 \pm 0.1$ \\
\hline & Mannose $5 \%$ & $>1,000$ & $0.89 \pm 0.04$ & $3.3 \pm 0.2$ \\
\hline & Mannose $10 \%$ & $626 \pm 31$ & $0.66 \pm 0.03$ & $3.5 \pm 0.2$ \\
\hline & Sucrose $5 \%$ & $>1,000$ & $0.59 \pm 0.27$ & $-2.3 \pm 0.1$ \\
\hline & Sucrose $10 \%$ & $>1,000$ & $0.84 \pm 0.21$ & $-1.5 \pm 0.1$ \\
\hline & Mannitol 5\% & $>1,000$ & $0.99 \pm 0.05$ & $-2.6 \pm 0.1$ \\
\hline & Mannitol I0\% & $>1,000$ & $0.80 \pm 0.04$ & $-I . I \pm 0 . I$ \\
\hline $\mathrm{T} 80$ & Glucose 5\% & $>1,000$ & $0.34 \pm 0.0 \mathrm{I}$ & $-2.4 \pm 0.1$ \\
\hline \multirow[t]{9}{*}{$(2.5 \% \mathrm{w} / \mathrm{v})$} & Glucose $10 \%$ & $>1,000$ & $0.39 \pm 0.11$ & $-2.5 \pm 0.1$ \\
\hline & Trehalose $5 \%$ & $>1,000$ & $0.38 \pm 0.05$ & $-3.4 \pm 0.1$ \\
\hline & Trehalose $10 \%$ & $>1,000$ & $0.42 \pm 0.02$ & $2.2 \pm 0.1$ \\
\hline & Mannose 5\% & $>1,000$ & $0.53 \pm 0.12$ & $2.3 \pm 0.1$ \\
\hline & Mannose $10 \%$ & $>1,000$ & $0.59 \pm 0.09$ & $3.5 \pm 0.1$ \\
\hline & Sucrose $5 \%$ & $>1,000$ & $0.38 \pm 0.06$ & $-3.5 \pm 0.11$ \\
\hline & Sucrose $10 \%$ & $>1,000$ & $0.42 \pm 0.01$ & $-2.5 \pm 0.11$ \\
\hline & Mannitol 5\% & $230 \pm 11$ & $0.28 \pm 0.05$ & $-2.5 \pm 0.11$ \\
\hline & Mannitol $10 \%$ & $294 \pm 7$ & $0.34 \pm 0.06$ & $-2.0 \pm 0.1$ \\
\hline PLXI88 & Glucose $5 \%$ & $>1,000$ & $0.24 \pm 0.17$ & $-3.4 \pm 0.2$ \\
\hline \multirow[t]{9}{*}{$(5 \% w / v)$} & Glucose $10 \%$ & $>1,000$ & $0.36 \pm 0.28$ & $-1.5 \pm 0.11$ \\
\hline & Trehalose 5\% & $64 I \pm 32$ & $0.55 \pm 0.05$ & $-5.4 \pm 0.3$ \\
\hline & Trehalose $10 \%$ & $677 \pm 30$ & $0.61 \pm 0.06$ & $1.2 \pm 0.1$ \\
\hline & Mannose 5\% & $478 \pm 22$ & $0.53 \pm 0.01$ & $1.2 \pm 0.1$ \\
\hline & Mannose $10 \%$ & $473 \pm 20$ & $0.75 \pm 0.17$ & $1.5 \pm 0.1$ \\
\hline & Sucrose $5 \%$ & $>1,000$ & $0.13 \pm 0.27$ & $-2.5 \pm 0.1$ \\
\hline & Sucrose $10 \%$ & $>1,000$ & $0.14 \pm 0.21$ & $-1.5 \pm 0.1$ \\
\hline & Mannitol 5\% & $>1,000$ & $0.68 \pm 0.06$ & $-3.5 \pm 0.1$ \\
\hline & Mannitol $10 \%$ & $>1,000$ & $0.80 \pm 0.01$ & $-1.7 \pm 0.1$ \\
\hline SD & Glucose 5\% & $15 \mid \pm 5$ & $0.28 \pm 0.02$ & $-37.8 \pm 2.6$ \\
\hline \multirow[t]{9}{*}{$(1.25 \% \mathrm{w} / \mathrm{v})$} & Glucose $10 \%$ & $332 \pm 16$ & $0.52 \pm 0.05$ & $-35.7 \pm 2.2$ \\
\hline & Trehalose 5\% & $135 \pm 1$ & $0.16 \pm 0.01$ & $-33.8 \pm 2.6$ \\
\hline & Trehalose $10 \%$ & $138 \pm 2$ & $0.19 \pm 0.03$ & $-34.7 \pm 2.2$ \\
\hline & Mannose 5\% & $202 \pm 3$ & $0.42 \pm 0.02$ & $-34.9 \pm 2.9$ \\
\hline & Mannose $10 \%$ & $>1,000$ & $0.94 \pm 0.08$ & $-42.2 \pm 1.1$ \\
\hline & Sucrose $5 \%$ & $216 \pm 10$ & $0.28 \pm 0.07$ & $-37.6 \pm 4.7$ \\
\hline & Sucrose $10 \%$ & $167 \pm 8$ & $0.27 \pm 0.03$ & $-34.9 \pm 2.9$ \\
\hline & Mannitol 5\% & $146 \pm 4$ & $0.21 \pm 0.04$ & $-40.2 \pm 1.1$ \\
\hline & Mannitol $10 \%$ & $139 \pm 2$ & $0.16 \pm 0.01$ & $-39.6 \pm 4.3$ \\
\hline
\end{tabular}

Note: Data are presented as mean \pm standard deviation.

Abbreviations: T80, Tween $80^{\oplus}$; PLXI88, Poloxamer 188 ${ }^{\oplus}$; SD, sodium deoxycholate monohydrate.

characterized by a negative surface charge $(\sim-30 \mathrm{mV})$, while the other nanoparticles and cryoprotectants showed a zeta potential close to neutrality (Table 4). This feature could explain the complexity of obtaining stable freeze-dried 
nanoparticles. The use of 5\% mannitol showed an acceptable increase of the mean size of T80-zein nanoparticles, while all the other formulations were characterized by aggregates and unstable structures upon rehydration. These results demonstrated the possibility of dehydrating SD-enriched zein nanoparticles by freeze-drying, providing access to a functional powdered formulation to be used in pharmanutraceutical application.

\section{Evaluation of cytotoxicity}

The safety evaluation of a new formulation is another fundamental issue to be addressed. Although zein has already been approved by the FDA, ${ }^{44}$ different amounts of polymeric nanoparticles were tested as a function of both polymer concentration and incubation time. K562 cells were used as a model of a non-adhesive cell line, while the A549 cells were investigated as models of a solid tumor.

The idea was to investigate the influence of surfactants on the cell viability as a function of the modulation of the interfacial tension existing between cell and plate, or as a function of their action on the cell membrane. A549 cells were used because it was demonstrated that a positive charge of a colloidal system could favor its uptake into lung cancer tissue. ${ }^{28}$ As shown in Figure 5, the surfactant-free zein nanoparticles exerted a certain cytotoxicity only after $72 \mathrm{~h}$ incubation at the greatest protein concentration tested; namely, $100 \mu \mathrm{g} / \mathrm{mL}$ of zein nanoparticles induced a decrease in cell viability of $25 \%-30 \%$ on both the cell lines, thus confirming the potentially safe use of this biomaterial (Figure 5).

Surfactant-coated zein nanosystems showed significant toxicity at a polymer concentration of $50 \mu \mathrm{g} / \mathrm{mL}$ after only $24 \mathrm{~h}$ incubation (Figure 5). Although the nanoparticles had been previously purified, the augmented toxicity, found in the formulations containing surfactant, contrarily to those composed exclusively of protein, could be due to the quantity of surfactant that remains in the colloidal structure, which reduces the surface tension between the culture plate and the cells (inducing their detachment), and also destabilizes the bilayer structure. ${ }^{38}$ This result demonstrated the maximum concentration of stabilizing surfactant in zein nanoparticles that can be used in in vitro experiments.

\section{Drug entrapment efficiency}

Taking into consideration the physicochemical features of zein nanoparticles as a function of the various environmental conditions, the $1.25 \%$ SD-coated zein nanoparticles were chosen as suitable drug carriers, and the EE\% of various molecules was investigated. Namely, rhodamine B was used as a model of a hydrophilic drug, while ATRA and Red Oil were chosen as lipophilic compounds. As reported in Table $5,100 \mu \mathrm{g} / \mathrm{mL}$ of hydrophobic compound was the maximum concentration supported by the colloidal system because macroaggregates formed at greater concentrations. In particular, EE values of $\sim 14$ and $\sim 28 \%$ were obtained for ATRA and Red Oil, respectively, when an initial concentration of $500 \mu \mathrm{g}$ was used (Table 5). The low degree of encapsulation that resulted for lipophilic drugs disagrees with other scientific investigations, even though zein does contain many hydrophobic moieties. ${ }^{39}$ This finding could be explained by the presence of high levels of xanthophylls strongly bound to yellow zein, thus inducing low EE values of lipophilic drugs with respect to decolorized zein. ${ }^{11}$ Conversely, the zein nanoparticles were able to retain a significant amount of the hydrophilic compound, thus evidencing their potential application as a useful carrier for water-soluble drugs (Table 5).

\section{Conclusion}

Zein is a very attractive polymer, which has been widely explored for novel applications in the fields of food science, pharmaceutics, and biomedicine. ${ }^{40} \mathrm{We}$ investigated yellow zein as a biocompatible material for developing innovative nanoparticles. The physicochemical characteristics of zein nanoparticles were influenced by the addition of various surfactants. The most suitable nanoparticle formulation to be proposed as a colloidal drug delivery system was obtained using $\mathrm{SD}(1.25 \% \mathrm{w} / \mathrm{v})$, which allowed the formation of stable zein nanoparticles with a mean size of $\sim 100 \mathrm{~nm}$, a low polidispersity index, and a negative surface charge $(\sim-30 \mathrm{mV})$. The SD-coated zein nanoparticles also showed high storage stability, and were not destabilized by heat treatments up to $50^{\circ} \mathrm{C}, \mathrm{pH}$ alterations, and the freeze-drying process, thus evidencing a great degree of maneuverability. Its incubation with $70 \% \mathrm{FBS}$ also confirmed the excellent stability and compatibility of this nanoparticle formulation in biological fluids, and its incubation with various cell lines revealed suitable safety up to $50 \mu \mathrm{g} / \mathrm{mL}$ of protein. The zein nanoparticles were able to retain different amounts of hydrophilic and lipophilic drugs, so ulterior investigations on the release rate of entrapped compounds as a function of the modulation of various parameters are in due course. Additional in vivo experiments on murine models are needed to evaluate the pharmacokinetic and biodistribution profiles of zein nanoparticles in order to appreciate the potential 


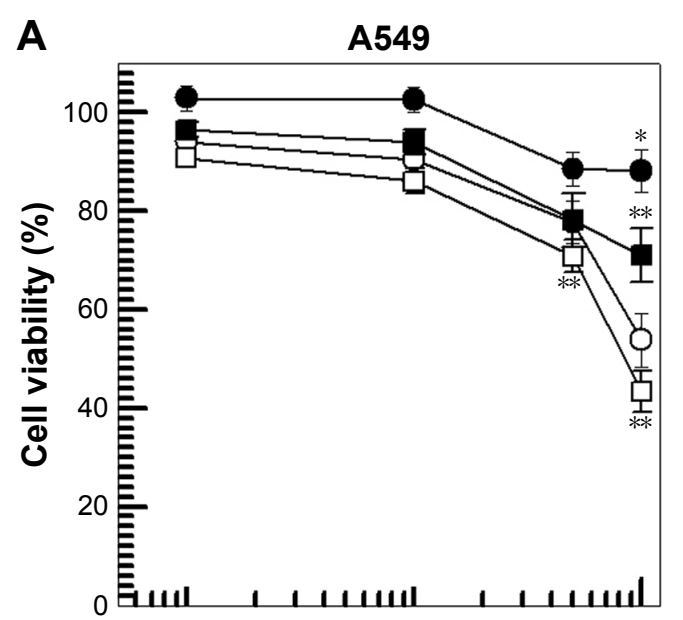

B

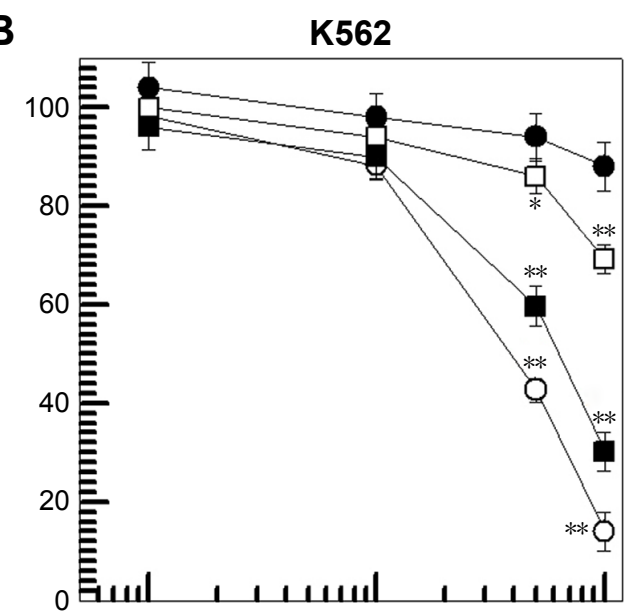

$24 \mathrm{~h}$
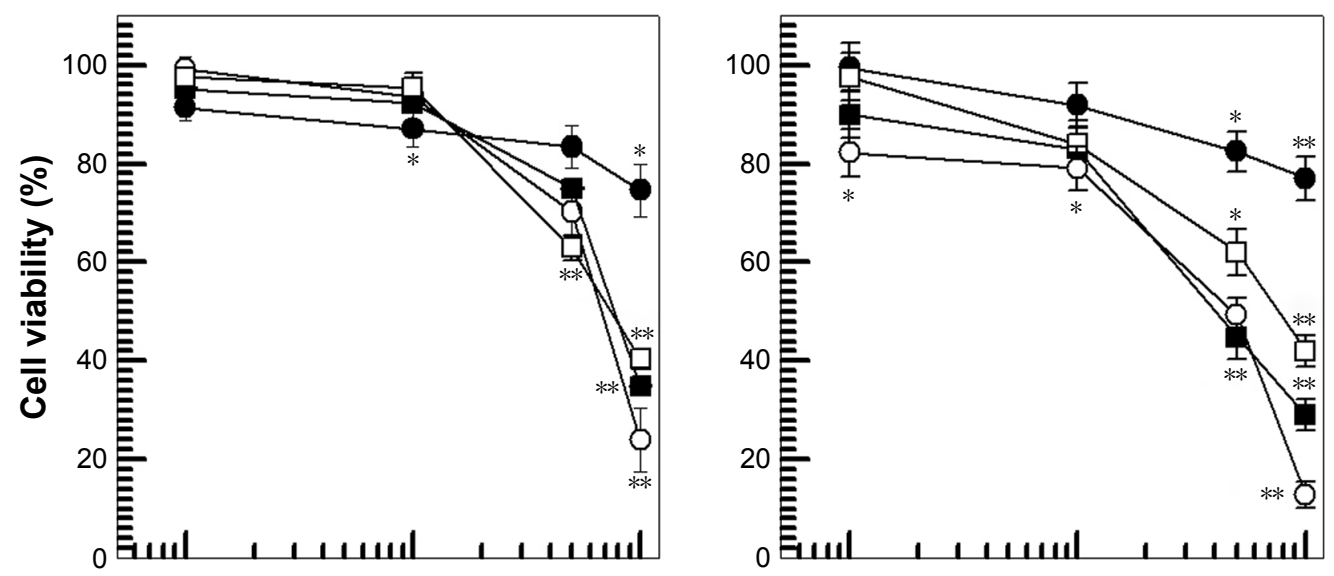

$48 \mathrm{~h}$
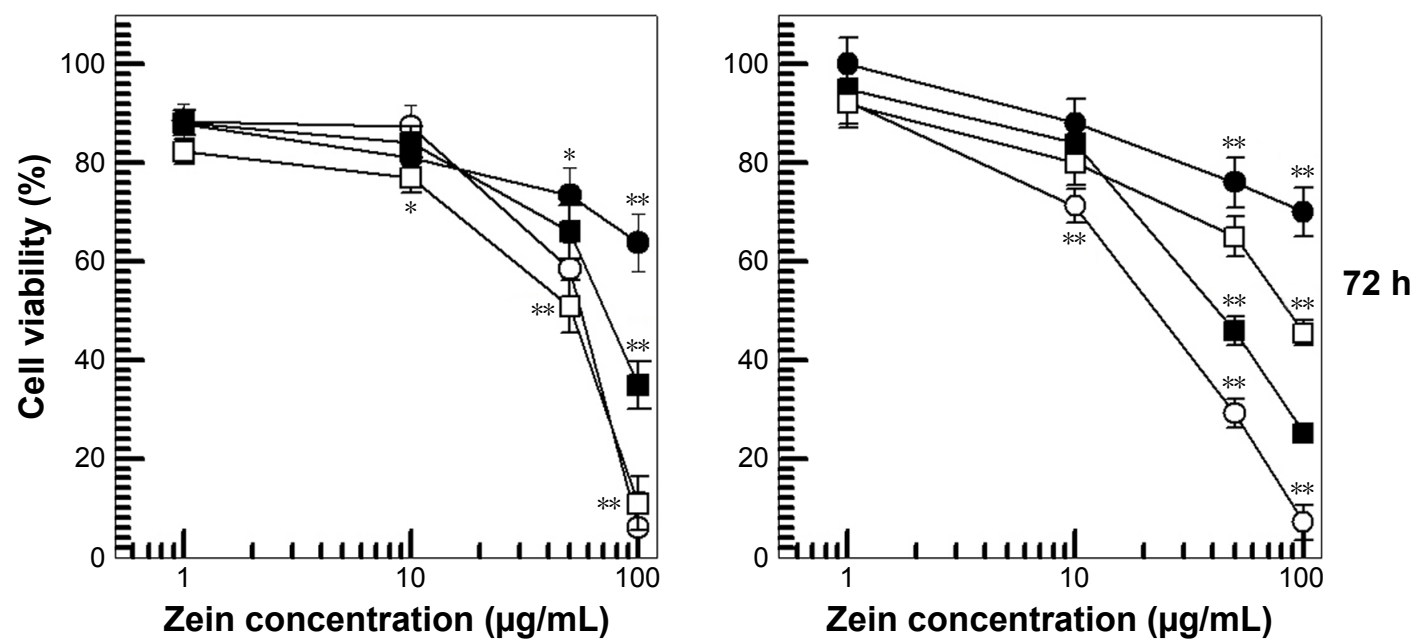

Zein concentration $(\mu \mathrm{g} / \mathrm{mL})$

Zein concentration $(\mu \mathrm{g} / \mathrm{mL})$

Surfactant free $-0-$ T80 $(2.5 \% \mathrm{w} / \mathrm{v})$

PLX188 (5\% w/v) - $\square-\operatorname{SD}(1.25 \% \mathrm{w} / \mathrm{v})$

Figure 5 Evaluation of in vitro cytotoxicity of zein nanoparticles on A549 (A) and K562 (B) cells as a function of zein concentration and incubation time. Data are the percentages of cellular viability as evaluated by MTT-testing. Results are the mean of four different experiments \pm standard deviation. Error bars, if not shown, are within symbols. Statistical analysis by one-way ANOVA and a posteriori Bonferroni $t$-test: $* P<0.05 ; * * P<0.001$.

Abbreviations: T80, Tween $80^{\circledR}$; PLXI88, Poloxamer $188^{\circledR}$; SD, sodium deoxycholate monohydrate.

applications of this nanoformulation as a drug delivery system. The peculiar properties of zein nanoparticles could be useful for their application in various scenarios (drug delivery, contrast agents for neuroimaging, optimization of radiotracers for nuclear medicine, radiosensitizers), as has been possible with other biopolymers. ${ }^{41,42}$

In fact, one of the most important goals to be reached will be the development of a novel nanomedicine able to increase 
Table $5 \mathrm{EE} \%$ of various active compounds in zein nanoparticles prepared by a protein concentration of $2 \mathrm{mg} / \mathrm{mL}$ and $1.25 \% \mathrm{w} / \mathrm{v}$ of $\mathrm{SD}$ as a function of the drug concentration initially used

\begin{tabular}{llll}
\hline Sample & $\begin{array}{l}\text { Amount of drug } \\
\text { used }(\mu \mathrm{g} / \mathrm{mL})\end{array}$ & EE $(\%)$ & $\begin{array}{l}\text { Drug } \\
\text { entrapped }(\mu \mathrm{g})\end{array}$ \\
\hline ATRA & 20 & $3.88 \pm 0.14$ & $3.88 \pm 0.15$ \\
& 50 & $7.3 \pm 0.29$ & $18.25 \pm 0.74$ \\
& 100 & $14.26 \pm 0.45$ & $71.3 \pm 2.85$ \\
& 200 & - & - \\
Red Oil & 20 & $10 \pm 0.4$ & $10 \pm 0.43$ \\
& 50 & $18 \pm 0.45$ & $45 \pm 1.8$ \\
& 100 & $28 \pm 0.66$ & $140 \pm 5.6$ \\
Rhodamine B & 200 & - & - \\
& 50 & $27.26 \pm 1.09$ & $27.26 \pm 1.09$ \\
& 100 & $29.14 \pm 1.16$ & $72.85 \pm 2.91$ \\
& 200 & $34.15 \pm 1.36$ & $170.75 \pm 6.83$ \\
& 200 & $65.4 \pm 2.62$ & $654 \pm 26.16$ \\
\hline
\end{tabular}

Abbreviations: EE\%, entrapment efficiency; ATRA, all-trans-retinoic acid; SD sodium deoxycholate monohydrate.

the pharmacological efficacy of the entrapped drug(s), but also to be used in imaging applications in order to obtain a useful theranostic nanomedicine. ${ }^{43}$

\section{Acknowledgments}

This work was financially supported by funds from the Department of Health Sciences. The authors are very grateful to Lynn Whitted for her revision of the language, and to $\mathrm{Mr}$ Francesco Frustaci, Mr Domenico Saturnino, and Mr Antonio Macrì (ISN-CNR) for their technical assistance.

\section{Author contributions}

All authors made substantial contributions to conception and design, acquisition of data, or analysis and interpretation of data; took part in drafting the article or revising it critically for important intellectual content; gave final approval of the version to be published; and agree to be accountable for all aspects of the work.

\section{Disclosure}

The authors report no conflicts of interest in this work.

\section{References}

1. Kim JK, Kim HJ, Chung JY, Lee JH, Young SB, Kim YH. Natural and synthetic biomaterials for controlled drug delivery. Arch Pharm Res. 2014;37(1):60-68.

2. Krats F. Albumin as a drug carrier: Design of prodrugs, drug conjugates and nanoparticles. J Control Release. 2008;132(3):171-183.

3. Malekzad H, Mirshekari H, Sahandi Zangabad P, et al. Plant proteinbased hydrophobic fine and ultrafine carrier particles in drug delivery systems. Crit Rev Biotechnol. 2018;38(1):47-67.
4. Reddy N, Yang Y. Potential of plant proteins for medical applications. Trends Biotechnol. 2011;29(10):490-498.

5. Irache JM, González-Navarro CJ. Zein nanoparticles as vehicles for oral delivery purposes. Nanomedicine (Lond). 2017;12(11): 1209-1211.

6. Zhang Y, Cui L, Che X, et al. Zein-based films and their usage for controlled delivery: origin, classes and current landscape. J Control Release. 2015;206:206-219.

7. Anderson TJ, Lamsal BP. Zein extraction from corn, corn products, and coproducts and modifications for various applications: a review. Cereal Chem. 2011;88(2):159-173.

8. Dong F, Padua GW, Wang Y. Controlled formation of hydrophobic surfaces by self-assembly of an amphiphilic natural protein from aqueous solutions. Soft Matter. 2013;9(25):5933-5941.

9. Zhang B, Luo Y, Wang Q. Effect of acid and base treatments on structural, rheological, and antioxidant properties of $\alpha$-zein. Food Chem. 2011;124(1):210-220.

10. Regier MC, Taylor JD, Borcyk T, Yang Y, Pannier AK. Fabrication and characterization of DNA-loaded zein nanospheres. J Nanobiotechnology. 2012;10:44.

11. Paliwal R, Palakurthi S. Zein in controlled drug delivery and tissue engineering. J Control Release. 2014;189:108-122.

12. Patel AR, Bouwens EC, Velikov KP. Sodium caseinate stabilized zein colloidal particles. J Agric Food Chem. 2010;58(23):12497-12503.

13. Lai LF, Guo HX. Preparation of new 5-fluorouracil loaded zein nanoparticles for liver targeting. Int J Pharm. 2011;404(1-2):317-323.

14. Luo Y, Teng Z, Wang Q. Development of zein nanoparticles coated with carboxymethyl chitosan for encapsulation and controlled release of vitamin D3. J Agric Food Chem. 2012;60(3):836-843.

15. Hu K, McClements DJ. Fabrication of surfactant-stabilized zein nanoparticles: A pH modulated antisolvent precipitation method. Food Res Int. 2014;64:329-335.

16. Lucio D, Martínez-Ohárriz MC, Jaras G, et al. Optimization and evaluation of zein nanoparticles to improve the oral delivery of glibenclamide. In vivo study using C. elegans. Eur J Pharm Biopharm. 2017;121:104-112.

17. Wu Y, Luo Y, Wang Q. Antioxidant and antimicrobial properties of essential oils encapsulated in zein nanoparticles prepared by liquid-liquid dispersion method. LWT - Food Sci Technol. 2012;48(2):283-290.

18. Zhang Y, Niu Y, Luo Y, et al. Fabrication, characterization and antimicrobial activities of thymol-loaded zein nanoparticles stabilized by sodium caseinate-chitosan hydrochloride double layers. Food Chem. 2014;142:269-275.

19. Li F, Chen Y, Liu S, et al. Size-controlled fabrication of zein nano/ microparticles by modified anti-solvent precipitation with/without sodium caseinate. Int J Nanomedicine. 2017;12:8197-8209.

20. Patel AR, Velikov KP. Zein as a source of functional colloidal nanoand microstructures. Curr Opin Colloid Interface Sci. 2014;19(5): 450-458.

21. Podaralla S, Perumal O. Influence of formulation factors on the preparation of zein nanoparticles. AAPS PharmSciTech. 2012;13(3): 919-927.

22. Hurtado-Lopez P, Murdan S. Zein microspheres as drug/antigen carriers: A study of their degradation and erosion, in the presence and absence of enzymes. J Microencapsul. 2006;23(3):303-314.

23. Hurtado-Lopez P, Murdan S. Formulation and characterisation of zein microspheres as delivery vehicles. J Drug Deliv Sci Technol. 2005; 15(4):267-272.

24. Cosco D, Cilurzo F, Maiuolo J, et al. Delivery of miR-34a by chitosan/ PLGA nanoplexes for the anticancer treatment of multiple myeloma. Sci Rep. 2015;5:17579.

25. Paolino D, Cosco D, Celano M, et al. Gemcitabine-loaded biocompatible nanocapsules for the effective treatment of human cancer. Nanomedicine (Lond). 2013;8(2):193-201.

26. Cosco D, Tsapis N, Nascimento TL, et al. Polysaccharide-coated liposomes by post-insertion of a hyaluronan-lipid conjugate. Colloids Surf B Biointerfaces. 2017;158:119-126. 
27. Cosco D, Paolino D, De Angelis F, et al. Aqueous-core PEG-coated PLA nanocapsules for an efficient entrapment of water soluble anticancer drugs and a smart therapeutic response. Eur J Pharm Biopharm. 2015;89:30-39.

28. Licciardi M, Paolino D, Mauro N, et al. Cationic supramolecular vesicular aggregates for pulmonary tissue selective delivery in anticancer therapy. ChemMedChem. 2016;11(16):1734-1744.

29. Cosco D, Rocco F, Ceruti M, Vono M, Fresta M, Paolino D. Selfassembled squalenoyl-cytarabine nanostructures as a potent nanomedicine for treatment of leukemic diseases. Int $J$ Nanomedicine. 2012; 7:2535-2546.

30. Cosco D, Federico C, Maiuolo J, et al. Physicochemical features and transfection properties of chitosan/poloxamer 188/poly(D,L-lactideco-glycolide) nanoplexes. Int J Nanomedicine. 2014;9:2359-2372.

31. Deo N, Jockusch S, Turro NJ, Somasundaran P. Surfactant interactions with zein protein. Langmuir. 2003;19(12):5083-5088.

32. Cosco D, Paolino D, Maiuolo J, et al. Ultradeformable liposomes as multidrug carrier of resveratrol and 5-fluorouracil for their topical delivery. Int J Pharm. 2015;489(1-2):1-10.

33. Chen H, Zhong Q. A novel method of preparing stable zein nanoparticle dispersions for encapsulation of peppermint oil. Food Hydrocoll. 2015;43:593-602.

34. Cosco D, Fattal E, Fresta M, Tsapis N. Perfluorocarbon-loaded micro and nanosystems for medical imaging: A state of the art. J Fluor Chem. 2015;171:18-26.

35. Dai L, Sun C, Wang D, Gao Y. The interaction between zein and lecithin in ethanol-water solution and characterization of zein-lecithin composite colloidal nanoparticles. PLoS One. 2016;11(11):e0167172.

36. Corbo C, Molinaro R, Parodi A, Toledano Furman NE, Salvatore F, Tasciotti E. The impact of nanoparticle protein corona on cytotoxicity, immunotoxicity and target drug delivery. Nanomedicine (Lond). 2016; 11(1):81-100
37. Kreuter J. Drug delivery to the central nervous system by polymeric nanoparticles: what do we know? Adv Drug Deliv Rev. 2014;71: 2-14.

38. Peetla C, Labhasetwar V. Effect of molecular structure of cationic surfactants on biophysical interactions of surfactant-modified nanoparticles with a model membrane and cellular uptake. Langmuir. 2009; 25(4):2369-2377.

39. Luo Y, Zhang B, Whent M, Yu LL, Wang Q. Preparation and characterization of zein/chitosan complex for encapsulation of $\alpha$-tocopherol, and its in vitro controlled release study. Colloids Surf B Biointerfaces. 2011;85(2):145-152.

40. Luo Y, Wang Q. Zein-based micro- and nano-particles for drug and nutrient delivery: A review. J Appl Polym Sci. 2014;131:40696.

41. Ganau M, Syrmos NC, D’Arco F, et al. Enhancing contrast agents and radiotracers performance through hyaluronic acid-coating in neuroradiology and nuclear medicine. Hell J Nucl Med. 2017;20(2):166-168.

42. Payne WM, Hill TK, Svechkarev D, Holmes MB, Sajja BR, Mohs AM. Multimodal imaging nanoparticles derived from hyaluronic acid for integrated preoperative and intraoperative cancer imaging. Contrast Media Mol Imaging. 2017;2017:9616791.

43. Thapa RK, Nguyen HT, Jeong JH, et al. Synergistic anticancer activity of combined histone deacetylase and proteasomal inhibitor-loaded zein nanoparticles in metastatic prostate cancers. Nanomedicine. 2017; 13(3):885-896.

44. CFR - code of federal regulations title 21, Sec. 184.1984 Zein [webpage on the Internet]. Silver Spring, MD: US Food and Drug Administration; 2017 [cited April 7, 2017]. Available from: https://www.accessdata.fda. gov/scripts/cdrh/cfdocs/cfcfr/CFRSearch.cfm?fr=184.1984. Accessed January 23, 2018. 


\section{Supplementary materials}

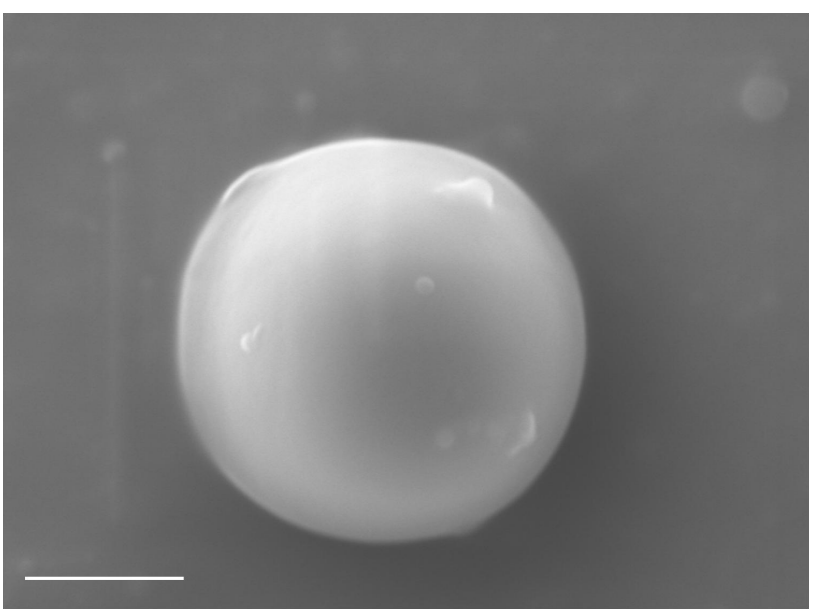

Figure SI Scanning electron microscope micrograph of zein nanoparticles characterized by a protein concentration of $2 \mathrm{mg} / \mathrm{mL}$. Scale bar $=100 \mathrm{~nm}$.
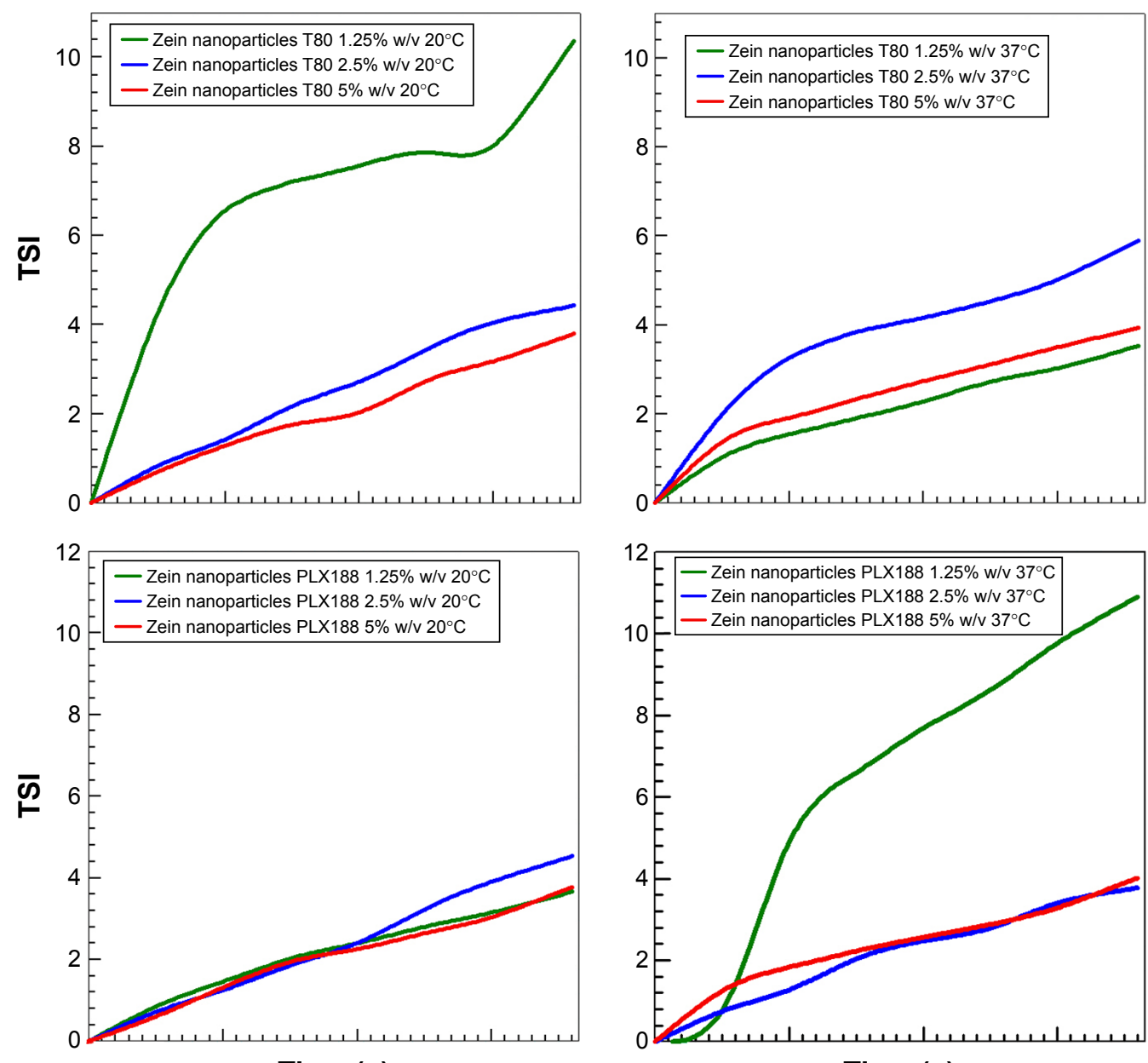

Time (s)

Time (s)

Figure S2 (Continued) 

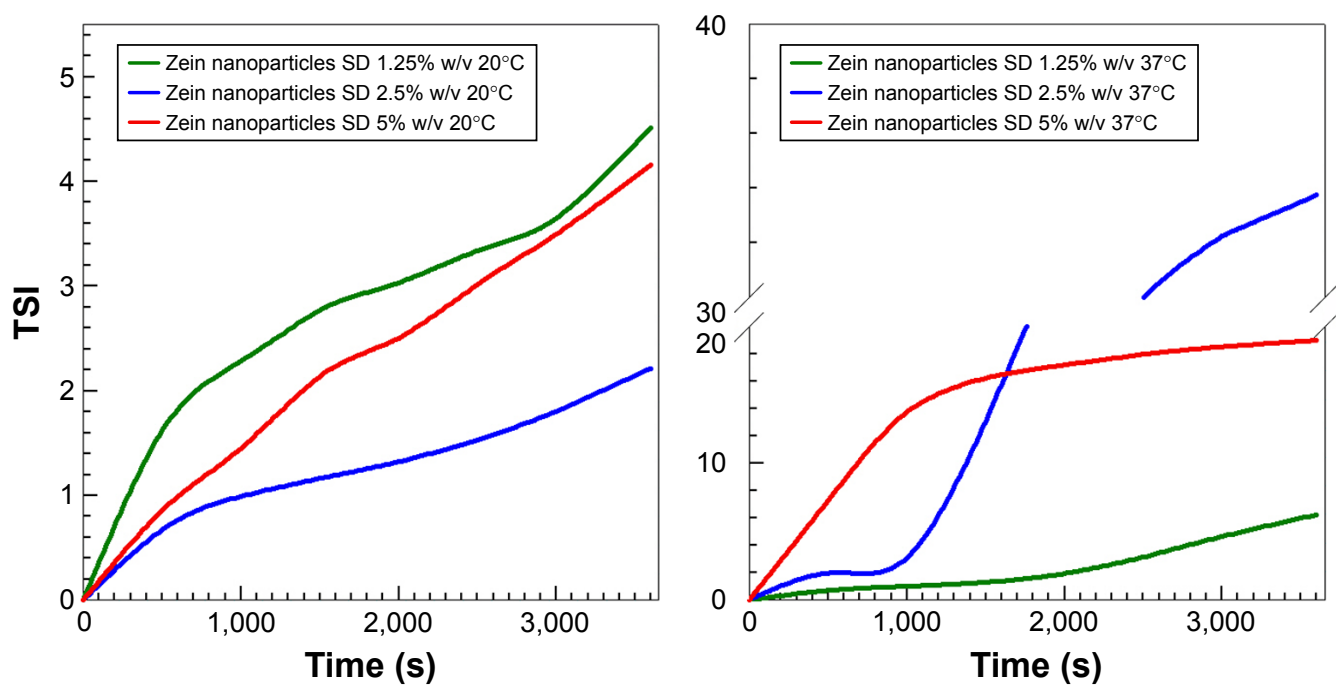

Figure S2 TSI of zein nanoparticles prepared by using $2 \mathrm{mg} / \mathrm{mL}$ of protein as a function of stabilizer concentration and incubation temperature. Abbreviations: TSI, Turbiscan Stability Index; T80, Tween $80^{\circledR}$; PLXI88, Poloxamer 188 ${ }^{\circledR}$; SD, sodium deoxycholate monohydrate.

\section{Publish your work in this journal}

The International Journal of Nanomedicine is an international, peerreviewed journal focusing on the application of nanotechnology in diagnostics, therapeutics, and drug delivery systems throughout the biomedical field. This journal is indexed on PubMed Central, MedLine, CAS, SciSearch ${ }^{\circledR}$, Current Contents ${ }^{\circledR} /$ Clinical Medicine,
Journal Citation Reports/Science Edition, EMBase, Scopus and the Elsevier Bibliographic databases. The manuscript management system is completely online and includes a very quick and fair peer-review system, which is all easy to use. Visit http://www.dovepress.com/ testimonials.php to read real quotes from published authors. 